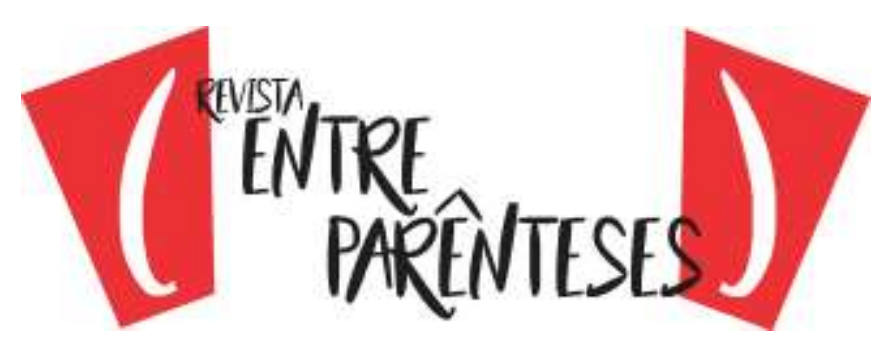

\title{
A FORMAÇÃO IDENTITÁRIA DO IMIGRANTE EM GAROTA, TRADUZIDA, DE JEAN KWOK
}

\author{
https://doi.org/10.32988/rep.v2n9.1158 \\ Victória Bezerra ${ }^{1}$ \\ Universidade do Estado do Rio de Janeiro \\ (vicbezerra12@gmail.com)
}

\begin{abstract}
Resumo: O romance Garota, traduzida, de Jean Kwok é uma apropriação contemporânea do bildungsroman e narra a trajetória de uma imigrante chinesa nos EUA. O presente artigo tem como objetivo analisar a reconfiguração identitária da protagonista, na perspectiva do modelo de aculturação bidimensional de John Berry (2004), dos estudos de Stuart Hall (2003) e Dennys Cuche (1999) acerca da identidade cultural e das considerações de Benedict Anderson (2008) sobre a identidade nacional.
\end{abstract}

Palavras-chave: Identidade cultural; aculturação; Jean Kwok.

\section{MIGRANT'S IDENTITY FORMATION IN GIRL IN TRANSLATION, BY JEAN KWOK}

Abstract: Girl in translation, by Jean Kwok, is a contemporary appropriation of bildungsroman and narrates the trajectory of a Chinese immigrant in the USA. This article aims to analyse the identity reconfiguration of the protagonist, from the perspective of the bidimensional model of acculturation of John Berry (2004), the studies of theorists such as Stuart Hall (2003) and Dennys Cuche (1999) about the cultural identity and considerations of Benedict Anderson (2008) on national identity.

Keywords: Cultural identity; Acculturation; Jean Kwok.

\section{LA FORMACIÓN IDENTITARIA DEL INMIGRANTE EN GIRL IN TRANSLATION, POR JEAN KWOK}

Resumen: Girl in Translation, es una apropiación contemporánea de un bildungsroman y narra la trayectoria de un inmigrante chino en los Estados Unidos. Este artículo tiene como objetivo analizar la reconfiguración de la identidad del protagonista, desde la perspectiva del proceso de aculturación bidimensional de John Berry (2004), los estudios de teóricos como los de Stuart Hall (2003) y Dennys Cuche (1999) sobre la identidad cultural y las consideraciones de Benedict Anderson (2008) sobre la identidad nacional.

Palabras-clave: Identidad cultural; aculturación; Jean Kwok.

\section{INTRODUÇÃO}

\footnotetext{
${ }^{1}$ Graduada em Letras - Português e Inglês pela Universidade do Estado do Rio de Janeiro (FFP). Mestranda do Programa de Pós-Graduação em Letras e Linguística - PPLIN/UERJ, na Área de Estudos Literários. Atua como revisora da Revista Soletras, periódico do PPLIN, vinculada ao Departamento de Letras da Faculdade de Formação de Professores. Membro integrante do projeto de pesquisa Migração, identidade e memória: representações do imigrante na literatura contemporânea em língua inglesa.
} 


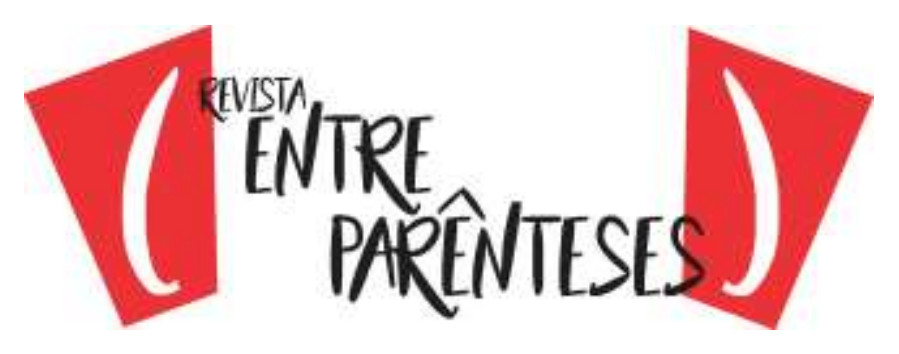

Em meio ao presente fenômeno da globalização, no qual os deslocamentos humanos são recorrentes, passou-se a pensar a questão identitária do indivíduo em trânsito, o modo como lida com os impasses e situações advindos do choque cultural, e, principalmente, o efeito deste sobre as identidades. $O$ indivíduo migrante nesse cruzamento de fronteiras encontra-se em um processo de aculturação (BERRY, 2004), que é uma parte importante no processo de reconfiguração identitária.

Os constantes deslocamentos e movimentos migratórios, dos séculos $\mathrm{XX}$ e XXI, fizeram com que o conceito, anteriormente considerado imutável, de identidade fosse transformado e compreendido como algo fluido, segundo os estudos de teóricos como Stuart Hall e Dennys Cuche. Conceitos como o de identidade nacional e identidade cultural, por exemplo, passaram a fazer parte do repertório crítico contemporâneo, sendo amplamente utilizados na análise de obras que têm como tema o deslocamento territorial. O sujeito dessas narrativas não é mais compreendido como detentor de uma identidade fixa, mas sim de uma identidade híbrida, que resulta da aculturação.

Tomando por base conceitos advindos do campo de investigação dos Estudos Culturais, este trabalho visa à análise da reconfiguração identitária no romance Garota, traduzida, de Jean Kwok, obra que se configura como uma apropriação do romance de formação tradicional, tendo como modelo Os Anos de Aprendizado de Wilhelm Meister, de Goethe, narra a trajetória de Kimberly, uma imigrante chinesa nos EUA. Ao longo do romance, analisaremos como se dá a trajetória da protagonista, a representação do choque cultural e a reconfiguração identitária da personagem, derivada do processo de aculturação.

\section{BREVE REFLEXÃO SOBRE A IDENTIDADE CULTURAL}

Ao longo da história, o homem sempre buscou mecanismos de identificação. Anteriormente, a identidade do sujeito era bem delimitada e subordinada a classificações por meio de categorias como nacionalidade, gênero, 


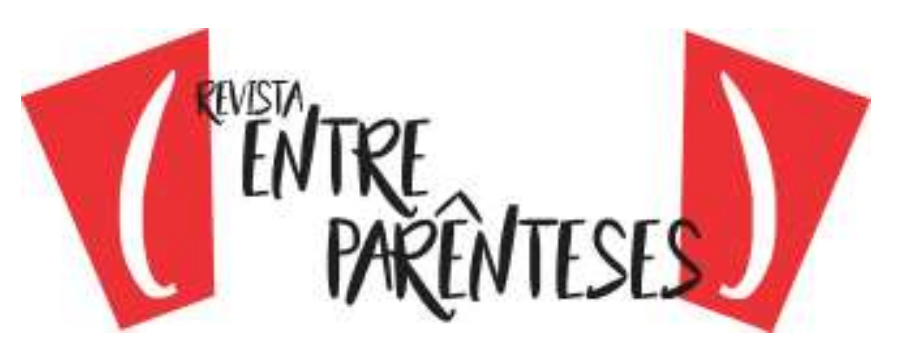

classe social e cor. O indivíduo, portanto, nascia com uma identificação que o acompanhava ao longo da vida.

Com base nesses critérios, os teóricos da identidade buscaram analisá-la a partir de perspectivas que podiam ser interpretadas como objetivistas ou subjetivistas. As primeiras reconhecem a identidade como delimitada através de características consideradas objetivas, como a origem comum (a hereditariedade, a genealogia), a língua, a cultura, a religião e o vínculo com um território (CUCHE, 1999, p. 180). As segundas baseiam-se no sentimento de identificação do indivíduo com um determinado grupo. Segundo Cuche (1999), ambas as perspectivas são problemáticas, pois enquanto a perspectiva objetivista interpreta a identidade como algo que independe do ser humano, a subjetivista a percebe como uma simples escolha do sujeito.

A esses primeiros modelos de análise, seguiram-se outros, com um enfoque relacional e situacional, segundo o qual a identidade do indivíduo seria formada a partir da relação de oposição entre grupos, resultante de uma negociação entre a identidade definida pelo próprio indivíduo, a autoidentidade, e a identidade definida por outros sujeitos, a heteroidentidade. A afirmação da identidade viria, portanto, de um processo de alteridade. A falha nesse processo resulta em uma identidade negativa, que pode levar ao estereótipo e ao estigma.

Claude Dubar (2009) corrobora a ideia de Cuche (1999) ao compreender o processo de identificação como o "resultado de uma dupla operação linguageira: diferenciação e generalização" (DUBAR, 2009, p. 13), na qual o sujeito obtém a sua singularidade em meio a um grupo. Isso resulta em um paradoxo, segundo Dubar (2009), pois a identidade é formada a partir das diferenças.

Stuart Hall (2003), por sua vez, entende a identidade a partir de três concepções que ele distingue como: 1) sujeito do lluminismo; 2) sujeito sociológico e; 3) sujeito pós-moderno. Com tais concepções, é possível perceber como o indivíduo moldou-se ao longo da história. Nos séculos XVII e XVIII, a identidade dos sujeitos era considerada imutável. À medida que a sociedade foi se tornando mais complexa e exigindo uma maior relação entre os sujeitos, formou-se uma conjuntura 


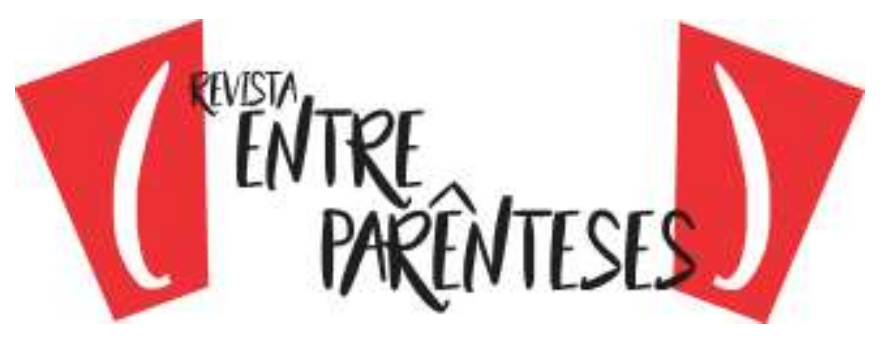

que, segundo Hall (2003), propiciou a concepção do sujeito sociológico, que tem sua identidade formada a partir da interação com o outro; perspectiva que se assemelha a teoria do looking glass, de Charles Cooley (1902), que mostra que a interação do sujeito com outras pessoas faz com que a visão de si mesmo e seu comportamento possam ser alterados. O sujeito sociológico torna-se um elo nessa cadeia identitária que culmina com o surgimento do sujeito pós-moderno, cuja identidade é fluida e fragmentada, tornando-se passível de um permanente processo de transformação.

A percepção dessa fluidez identitária leva à percepção de que a identidade nacional e a cultura serviam ao propósito de unificação e eram elaborações discursivas. Segundo Benedict Anderson (2008), o que se entende como pátria é, na verdade, um construto, "uma comunidade política imaginada" (ANDERSON, 2008, p. 32), pois não há a possibilidade de todos os indivíduos de uma determinada comunidade se conhecerem, porém estes estariam unidos através de uma imagem nacional construída. A utilização de mitos, imagens e tradições se tornam importantes para a criação de uma narrativa nacional, para unir um determinado povo.

Após o século XIX, com os constantes deslocamentos migratórios e a globalização, intensificou-se o questionamento dos elementos configuradores das identidades nacionais, pois as fronteiras geográficas, que dividem e demarcam territórios, passaram a se tornar menos perceptíveis, uma vez que o sujeito em trânsito se desterritorializa, adquire uma percepção de si mais cosmopolita, a partir do contato com diversas culturas. Segundo Lobo (2015), a fronteira adquire uma concepção mais metafórica, pois "a fronteira já não é símbolo de transgressão, mas sim de fluidez e hibridismo, reconfigurando-se na expressão de quem constrói a sua identidade entre-mundos" (LOBO, 2015, p. 47). Assim, o sujeito não possui mais uma identidade fixa, pois ao se deslocar, a aculturação se faz presente, o que vai levar a identidade a um entrelugar, o espaço de contato entre culturas que Homi Bhabha denominou terceiro espaço.

\section{A ACULTURAÇÃO E O ENTRELUGAR}




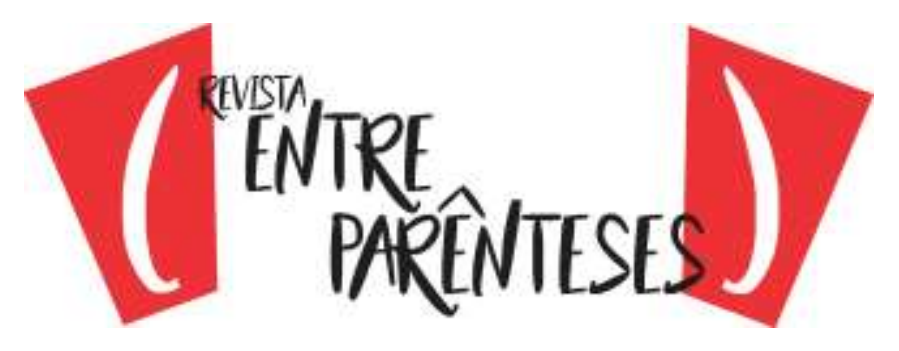

A passagem de um indivíduo de uma sociedade a outra faz com que esse sujeito migrante desenvolva estratégias para se adaptar à nação de acolhimento, pois abandona o contexto cultural e social no qual foi criado e se dirige uma sociedade com uma cultura diferente da sua.

Essas estratégias e comportamentos foram estudados por John Berry (2004), um psicólogo intercultural, que, contrapondo-se a uma visão unidimensional que previa ser a assimilação o único processo possível de adaptação a um novo lugar, propõe uma nova perspectiva de análise que se desvincula desse olhar hegemônico. A perspectiva de Berry (2004) é bidimensional e parte do princípio de que há alguns fatores chave que influenciam o modo dos sujeitos passarem pelo processo de aculturação. Há quem entre no processo voluntariamente, como os imigrantes, e os que são forçados a aculturar-se, como os refugiados e expatriados. Ao migrar, seja por qual motivo for, o indivíduo necessita reterritorializar-se e o faz segundo dois movimentos de igual importância: o que visa à manutenção da identidade cultural de origem e o que visa à relação com os outros. Esses dois movimentos correspondem a duas dimensões do processo adaptativo e podem ser divergentes.

As relações entre grupos vão ter um grau de contato diferente, uma vez que as interações não acontecem uniformemente, bem como a manutenção da cultura e identidade apresentada pelos grupos também vai diferir. As consequências dessas relações afetam os grupos envolvidos, os dominantes (da sociedade de acolhimento) e não-dominantes (dos imigrantes).

Berry (2004) investiga as "atitudes de aculturação" (BERRY, 2004), ou seja, os modos de adesão à sociedade local, a partir da observação das estratégias praticadas pelos grupos não-dominantes e dominantes, mesmo que de forma inconsciente, bem como o grau de contato entre eles. Dessa maneira, quando os grupos não-dominantes não têm o desejo de manter a identidade cultural de origem e a sua interação como o grupo dominante é máxima, acaba ocorrendo a assimilação. 


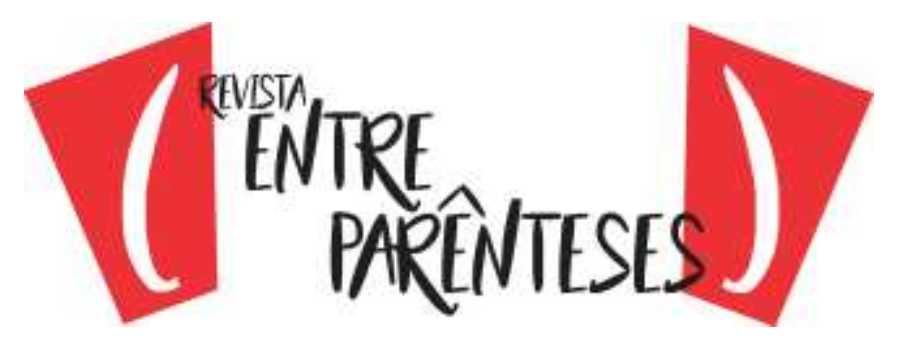

No entanto, a negação do contato entre culturas e a busca de manutenção de sua cultura própria, chama-se segregação, quando é forçada pelo grupo dominante e separação, quando é ocasionada pelo grupo não-dominante.

O grupo não-dominante pode também adotar uma estratégia de marginalização, quando não há interesse no contato intergrupal e a impossibilidade de manutenção da própria identidade cultural é impossível.

Segundo Berry (2004), a estratégia mais comum nos processos migratórios é a integração, resultante da manutenção da herança cultural e da interação entre culturas.

Todas essas estratégias resultam das relações de alteridades intergrupais e fazem parte do processo de aculturação e concorrem para a reconfiguração identitária do sujeito. Essas relações de alteridade podem também gerar estereótipos e o preconceito, que são construções sociais repetidas por meio do discurso.

A reconfiguração identitária ocorre, então, como resultado de um processo de aculturação. O indivíduo que antes se via ligado a somente um território e uma cultura, ao vivenciar uma tradução cultural acaba por se aculturar no entrelugar, que, segundo Silviano Santiago, no ensaio "O Entrelugar do Discurso Latino-Americano", é o espaço no qual o indivíduo vai intermediar suas identidades a partir de uma "tensão entre o apelo do enraizamento e a tentação da errância" (HANCIAU, 2005, p. 4-5). Ainda, "é nesse espaço do entrelugar que habita a différance e que sujeitos híbridos são constituídos" (RIBEIRO \& PRAZERES, 2015, p. 38). É onde ocorre a negociação entre culturas, responsável pela construção de identidades híbridas.

A percepção desses conceitos permite a compreensão dos fenômenos que ocorrem nas sociedades contemporâneas, sujeitas a um intenso fluxo migratório. A partir de suas experiências, o sujeito migrante pode subverter discursos que lhes são impostos como essenciais, ressignificando-os.

\section{A RECONFIGURAÇÃO IDENTITÁRIA EM GAROTA, TRADUZIDA}




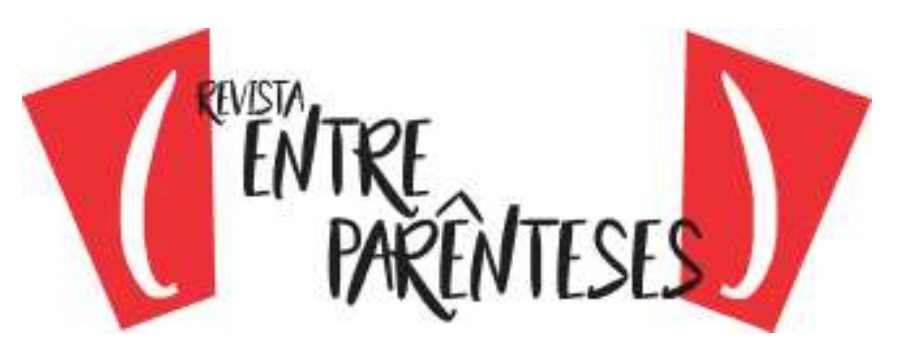

O romance Garota, traduzida foi escrito por Jean Kwok e teve sua publicação em 2010, nos EUA, e, em 2011, no Brasil. A autora, Jean Kwok, é uma imigrante que, aos 5 anos, deslocou-se com sua família, da China para os Estados Unidos, onde viveram, inicialmente, em condições desfavoráveis. Kwok necessitou trabalhar com sua família em uma fábrica mesmo sendo ainda bem jovem. Destarte, é possível perceber uma forte influência da biografia da autora no romance, muito embora, em uma entrevista, ela afirma que

[...] Garota, Traduzida é um trabalho de ficção. Ainda que alguns elementos da história tenham sido baseados em eventos da vida real, o presente enredo foi criado para atrair o leitor a um mundo estranho e real (KWOK, 2011, entrevista online. Tradução nossa). ${ }^{2}$

Garota, traduzida constitui-se como uma apropriação contemporânea do bildungsroman $^{3}$, com base no modelo do romance de Goethe, Os anos de aprendizado de Wilhem Meister (1795), uma vez que é um romance que acompanha a jornada do protagonista desde a sua infância até a vida adulta, em busca de definição da própria identidade. Tal modelo era originalmente centrado em personagens masculinos e membros da burguesia, refletindo a cultura e aspectos históricos da época de sua concepção. Com o passar do tempo, o bildungsroman caiu em desuso e, embora tenha havido variações com um enfoque feminino, havia nelas a mediação obrigatória de uma figura masculina, que funcionava como tutor, e tematicamente eram voltadas para o amor e o casamento. É nesse sentido que o romance Garota, traduzida se configura como uma apropriação contemporânea do bildungsroman, pois não apenas subverte o modelo tradicional, mas apresenta um enfoque feminino em que a formação ocorre efetivamente em decorrência das escolhas da protagonista.

\footnotetext{
2 [...] But I have to stress that Girl in Translation is by all measures a work of fiction. Although some elements of the story were based upon real-life events, the actual plotline itself was created to entice the reader into a strange and true world. (KWOK, 2011, entrevista online).

${ }^{3}$ Romance de formação.
} 


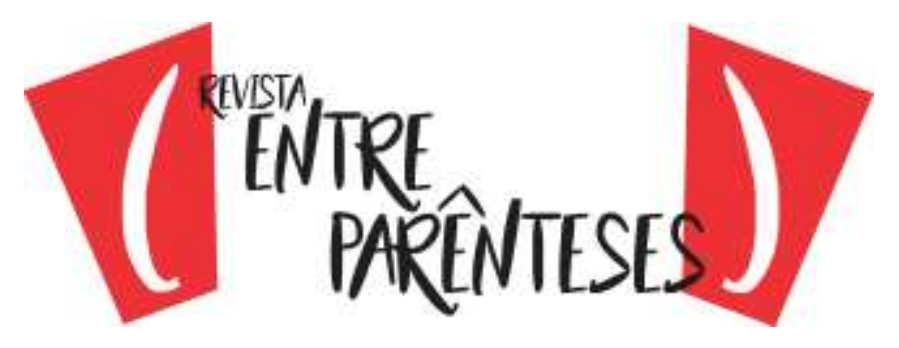

O romance narra a história de Ah-kim Chang, que, aos 11 anos e após o falecimento do pai, emigra com a mãe de Hong Kong para os Estados Unidos. Ao longo da história, acompanhamos o modo como a personagem enfrenta o choque cultural, as estratégias de aculturação que adota e sua reconfiguração identitária.

Tia Paula, a tia da protagonista, é quem fica responsável por viabilizar a viagem, a moradia, o trabalho e a escola para a irmã e a sobrinha. Ainda que possamos ver tais atitudes como generosas, percebe-se que, na verdade, Paula é movida por um sentimento de inveja e tenta sabotar algumas conquistas da protagonista.

Já na chegada Ah-kim enfrenta o primeiro de uma série de obstáculos, já que em Hong Kong, ambas viviam em situação financeira confortável até o falecimento do pai. A casa onde passam a viver, localizada no Brooklyn, em uma área desfavorecida, se difere daquela em que ambas moravam em Hong Kong e está em péssimas condições, Kimberly a descreve assim:

Eu estava de pé na cozinha. Um vento entrava pelas janelas à direita, assobiando. Perguntei-me por que a mãe as abrira. Então percebi que ainda estavam fechadas. Só que quase todos os vidros ou estavam faltando, ou estavam quebrados. [...] Uma grossa camada de pó cobria a pequena mesa da cozinha e a enorme pia, branca e lascada. Eu tentava me desviar das baratas mortas [...] As paredes apresentavam rachaduras em alguns lugares $e$ protuberâncias em outros [...] (KWOK, 2011, p. 9).

Mesmo sendo ainda criança, a protagonista percebe as atitudes de sua tia ao chegarem à nova casa,

\begin{abstract}
Percebi então a verdade. Ela fizera tudo de propósito: permitira que fizéssemos a mudança em um dia de semana, em vez de no fim de semana, e nos dera alguns presentes no último minuto. Usando a fábrica como desculpa, queria nos largar ali e ir embora rapidamente, enquanto ainda estávamos agradecendo sua bondade. Tia Paula não iria nos ajudar. Estávamos sozinhas. (KWOK, 2011, p. 10).
\end{abstract}

Esse impacto, bem como os subsequentes vivenciados tanto pela protagonista quanto por sua mãe, faz com que elas percebam que o sonho americano é, na verdade, uma ilusão. 


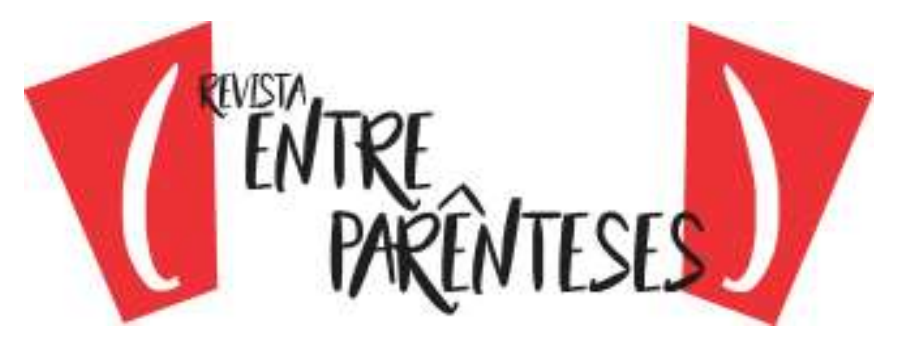

A identidade de Ah-kim é posta em xeque desde o início, quando Tia Paula insiste para que o seu nome seja americanizado, se modo que não sejam confundidas com imigrantes recém-chegadas. Dessa maneira, ela passa a ser chamada de Kimberly. A maioria das personagens trata a protagonista pelo nome americano, exceto sua mãe.

A partir daí, Kimberly passa a viver uma vida dupla: durante o dia vai à escola, mas à noite trabalha, com sua mãe, na fábrica de tecidos que pertence à sua tia. Nesse ponto, percebemos que a autora, de certo modo, denuncia a realidade de muitos imigrantes, exposta por meio da fala de Tia Paula sobre o cotidiano dos imigrantes na fábrica: "- Elas vêm para essa mesa ainda crianças e saem de lá já avós - disse tia Paula piscando um olho. - É o ciclo da vida na fábrica" (KWOK, 2011, p. 27). Essa passagem do romance aponta para a imobilidade social imposta ao imigrante. Kimberly percebe que, além dos adultos e idosos, há crianças trabalhando na fábrica para completar a renda familiar. Fica claro o mecanismo de exclusão que opera na sociedade americana, pois as regras e condições de vida disponíveis para os cidadãos brancos não são as mesmas para os imigrantes,

Desconfiei de que a maioria das outras crianças estava na fábrica pelos mesmos motivos que eu. Não eram contratadas, mas não tinham outro lugar para ir, e seus pais precisavam de sua ajuda. Como a mãe me explicou mais tarde, todos os empregados eram, secretamente, pagos por peça. [...] $\mathrm{Na}$ escola, aprendi que $\mathrm{o}$ pagamento por peça era ilegal, mas a regra era para pessoas brancas, não para nós. (KWOK, 2011, p. 30-31).

A escola é, para a personagem, o local onde o choque cultual é mais evidente, pois é o ambiente no qual Kimberly tem contato com um sistema educacional totalmente diferente do qual ela estava habituada. Ao contrário do sistema educacional chinês, que tem uma estrutura hierarquizada e firme, o sistema estadunidense é menos rígido e mais centrado no aluno. Sumei (2018) aponta tal diferença,

$\mathrm{Na}$ China, a aula pertence à professora / ao professor. Quando o(a) professor(a) ensina, os alunos ouvem com atenção, tomando notas e 


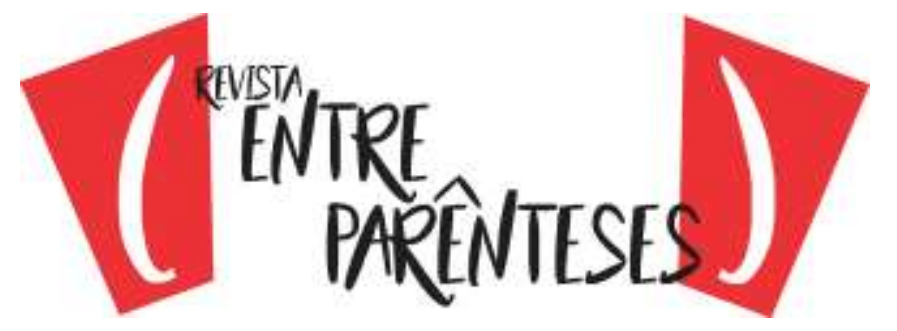

tomando por base livros didáticos e respostas dos professores; é uma educação de ensinamento. Existe falta de uma comunicação estreita entre estudantes e professores, resultando numa aceitação passiva do conhecimento por parte dos alunos. [...] Os métodos de ensino são muito diferentes, para diferentes fins. Nas aulas na China, os professores ensinam principalmente conhecimentos e os alunos precisam de memorizar e aplicar esses conhecimentos. No entanto, nas aulas ocidentais, o professor orienta os alunos para que pensem e se expressem, e é uma aula dirigida para os alunos. (SUMEI, 2018, p. 28-29).

Esse tipo de choque fica evidente nos primeiros dias de aula de Kimberly, quando ela senta de forma ereta, diferentemente dos outros alunos, que adotam uma postura mais relaxada, e é repreendida pelo professor.

$\mathrm{O}$ choque cultural é comportamental, mas também linguístico. Ainda que Hong Kong tenha sido uma colônia britânica, Kimberly está habituada a uma variante diferente do inglês e quando se comunica com os outros personagens há divergências de compreensão, que são retratadas no romance. No exemplo a seguir, a personagem pede uma informação e não compreende algumas palavras: "- Pega o corredor, dois lances de espada, a sala de aula é a pinheira à esquerda disse ela, apontando para frente (...) Entendi apenas que teria de seguir em frente" (KWOK, 2011, p. 22).

Ainda em relação à questão do idioma, há pouca aceitação por parte do grupo dominante, neste caso representado na figura do professor Bogart, que se aborrece com o fato de Kimberly não falar o inglês estadunidense,

- Escoltou o que eu disse?

- Pede desculpa, senhor - murmurei. [...] Embora eu tivesse tido aulas de inglês básico, em Hong Kong, a pronúncia do meu velho professor não se parecia em nada com o que eu andava ouvindo no Brooklyn.

- Pe-ço - disse ele, enunciando as sílabas. - Peço desculpas. -Peço desculpas - disse eu.

Meus erros de inglês o aborreciam, isso era certo, mas eu não sabia por quê. (KWOK, 2011, p. 24).

$\mathrm{Na}$ China era considerada uma aluna exemplar, mas nos Estados Unidos ela se sente frustrada por não corresponder às expectativas. As interações 


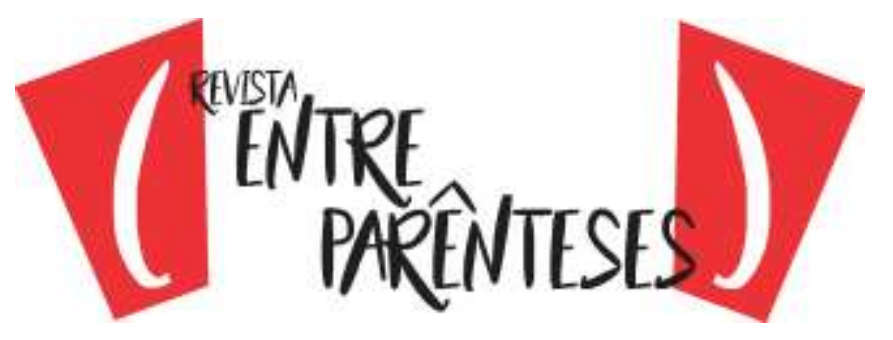

malsucedidas na escola, como as citadas acima, e as notas baixas fazem com que Kimberly passe a evitar a escola, mas logo, a personagem compreende que apenas por meio dos estudos poderá prover uma vida melhor para si e sua mãe.

Ao longo da trajetória de Kimberly, podemos perceber como o processo de aculturação ocorre. No início, há uma certa resistência de ambos os lados, tanto por parte das pessoas, que se recusam a interagir com ela, quanto dela mesma, que encontra empecilhos ao relacionamento com o meio. Com o passar do tempo, Kimberly adota uma postura mais receptiva, mas, ainda assim, se mantém reservada sobre sua vida pessoal, tendo poucas amizades.

A personagem não busca a assimilação, pois deseja reter a memória da sua cultura, sua tradição e de seu território de origem, que servem como uma espécie de refúgio, trazendo conforto. Essa memória é parcialmente recuperada por meio da comunidade de Chinatown, que segundo Kimberly, "se parecia muito com Hong Kong" (KWOK, 2011, p. 25), o que colabora para a manutenção de laços com a comunidade de origem,

a única alegria que tínhamos eram nossas visitas ao templo Shaolin de Chinatown [...] Lá eu encontrava meu refúgio. O templo era administrado por autênticas monjas chinesas [...] Eu me sentia em paz naquele templo. Era como se jamais tivéssemos saído de Hong Kong (KWOK, 2011, p. 127)

A mãe de Kimberly constitui um empecilho para um processo mais rápido de aculturação, pois se recusa a aprender o inglês e insiste e manter os elos com sua herança cultural. A protagonista passa, então, a assumir a posição de elo entre a mãe e a sociedade estadunidense: "eu ocupei o espaço que minha mãe não poderia ocupar. Ela não aprendera inglês, portanto assumi os encargos que exigiam alguma interação com o mundo além de Chinatown" (KWOK, 2011, p. 125).

A vida dupla de Kimberly tem forte influência nas relações amorosas, já que ela não se permite envolver romanticamente com os garotos de sua escola. $A$ única pessoa com quem ela se envolve romanticamente é Matt, um rapaz também imigrante, que também trabalha na fábrica. Esse relacionamento resulta em uma 


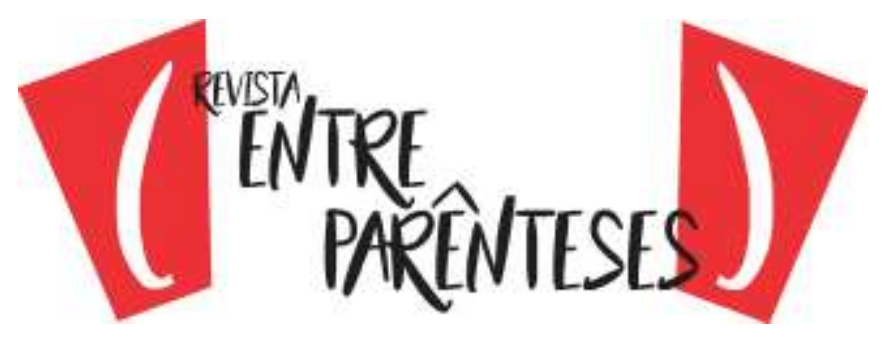

gravidez, que ela opta por esconder por não querer se unir a outra pessoa por obrigação. A essa altura, Kimberley já havia se tornado suficientemente independente e acreditava ser apta a construir sua própria trajetória.

As mudanças sofridas pela personagem perpassam a compreensão do sistema cultural estadunidense, ao qual busca integrar-se sem se esquecer de sua cultura de origem. Para obter certos benefícios, como obter uma bolsa de estudos, Kimberly opta por fazer o teste de naturalização, imprescindível à obtenção da cidadania americana. Situada no entrelugar a que todos os imigrantes são relegados, Kimberly é capaz de aculturar-se a contento. Nesse processo, sua identidade passa a ser híbrida, o fruto da negociação entre culturas.

Ao final do romance, sua reconfiguração identitária se completa. Kimberly se torna cirurgiã pediátrica e cuida sozinha de seu filho, Jason, que, como imigrante de segunda geração, domina a língua e se integra com facilidade à cultura estadunidense.

\section{CONSIDERAÇÕES FINAIS}

No romance Garota, traduzida, Jean Kwok elabora uma representação ficcional do processo de aculturação de uma imigrante chinesa nos Estados Unidos. Partindo de uma breve retrospectiva de conceitos inerentes aos estudos sobre a identidade, apresentamos as características gerais do modelo bidimensional de aculturação de John Berry e discorremos sobre as estratégias normalmente adotadas pelos imigrantes em sua relação com os grupos sociais dos países de acolhimento.

Demonstramos, também, que, vivendo no espaço intersticial do entrelugar, esses imigrantes necessitam lutar contra um processo de exclusão que os relega a uma existência marginalizada. A dissolução do sonho americano tem início à medida que eles se defrontam com dificuldades que, para alguns, se mostram intransponíveis, restando a alternativa do trabalho ilegal, que acaba se perpetuando e sendo transmitido às gerações seguintes. 


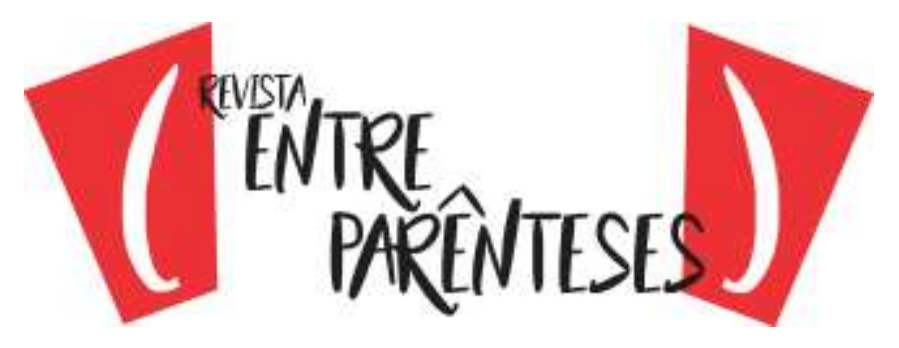

Por fim, através da subversão do modelo paradigmático do bildungsroman, de Goethe, o romance nos permite acompanhar a trajetória bemsucedida da personagem, expondo os impasses e as soluções advindas do processo de aculturação a que é submetida. Kimberly supera as barreiras sociais e linguísticas, integrando-se ao meio social, sem, no entanto, abrir mão dos elementos identificadores de sua origem. Essa integração é resultante de uma negociação entre culturas, mas também da adesão a determinados critérios que até hoje são condição sine qua non para a aceitação na sociedade estadunidense: o domínio do inglês, a educação formal e o sucesso econômico.

\section{Referências}

ANDERSON, Benedict. Comunidades imaginadas. São Paulo: Companhia das Letras, 2008.

BERRY, John Widdup. Migração, aculturação e adaptação. In: DEBIAGGI, Sylvia Dantas; PAIVA, Geraldo José de (orgs). Psicologia, e/imigração e cultura. São Paulo: Casa do Psicólogo, 2004.

COOLEY, Charles Horton. Human nature and the social order. New York: Charles Scribner's Sons, 1902.

CUCHE, Dennys. Cultura e identidade. In: ciências sociais. Bauru: EDUSC, 1999, p. 175-202.

A noção de cultura nas

DUFOURMANTELLE, Anne. Anne Dufourmantelle convida Jacques Derrida a falar da hospitalidade. Trad. Antonio Romane. São Paulo: Escuta, 2003.

DUBAR, Claude. A crise das identidades: A interpretação de uma mutação. São Paulo: Edusp, 2009.

HALL, Stuart. A identidade cultural na pós-modernidade. Trad. Tomaz Tadeu da Silva e Guacira Lopes Louro. 7. ed. Rio de Janeiro: DP\&A, 2003.

HANCIAU, Núbia. O entrelugar. In: Figueiredo, Eurídice. Conceitos de literatura e cultura. Juiz de Fora: Editora UFJF/Niterói, RJ: EdUFF, 2005, p. 215-241. 


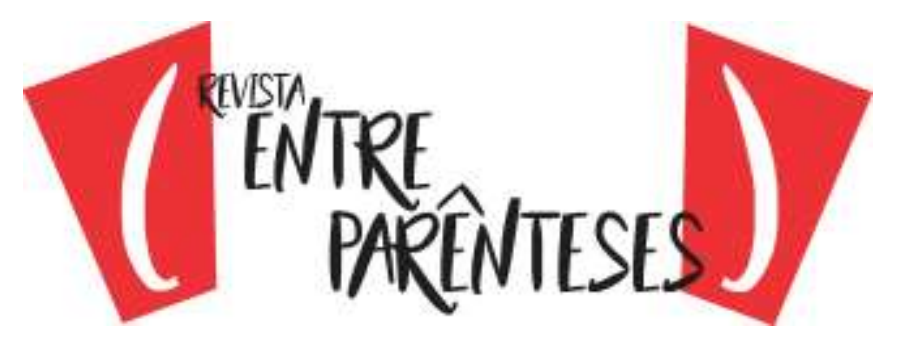

KWOK, Jean. Garota, traduzida. Tradução de Paulo Afonso. Rio de Janeiro: Objetiva, 2011.

An interview with Jean Kwok, Author Girl in translation. [Entrevista concedida a] Riverhead Books. [Republicada por] Reading Group Guides. [S.I.], 2011. Disponível em: https://www.readinggroupguides.com/blog/2011/05/26/aninterview-with-jean-kwok-author-girl-in-translation. Acesso em: 14 jun. 2020.

LOBO, Patrícia Alves de Carvalho. Chicanas em busca de território: A herança de Gloria Anzaldúa. 2015. 442 f. Tese (Doutorado em Estudos de Literatura e de Cultura) - Universidade de Lisboa, Lisboa, 2015.

PRAZERES, Lílian Lima Gonçalves dos.; Miglievich-Ribeiro, Adelia. A produção da subalternidade sob a ótica pós-colonial (e decolonial): algumas leituras. Temáticas, Campinas, SP, 23, (45/46), fev./dez, 2015, p.25-42.

SUMEI, Zou. Análise de diferenças culturais entre a educação chinesa e a ocidental. 2018. 57 f. Dissertação (Mestrado em Português como Língua Segunda ou Estrangeira) - Universidade Nova de Lisboa, Lisboa, 2018. Disponível em: <https://run.unl.pt/bitstream/10362/37776/1/\%E7\%BB\%88\%E7\%A8\%BF\%20Disserta c\%CC\%A7a\%CC\%83o-Ta\%CC\%82nia.pdf>. Acesso em: 12 jun. 2020.

Recebido em: 19/06/2020

Aceito em: 07/10/2020 